\section{A first ReCORd of AbRYNa RegISPetri PAIVA, 1860 (CerAmbycidae: LAMIINAE: PTEROPLIINI) AND ITS REDESCRIPTION FROM INDIA}

\section{H.V. Ghate ${ }^{1}$ \& B.K. Agarwala ${ }^{2}$}

${ }^{1}$ Post-Graduate Research Centre, Department of Zoology, Modern College, Shivajinagar, Pune, Maharashtra 411005, India

${ }^{2}$ Ecology and Biodiversity Laboratories, Department of Zoology, Tripura University, Surymanainagar, Tripura 799022, India ${ }^{1}$ hemantghate@gmail.com, ${ }^{2}$ bagarwala00@gmail.com (corresponding author)

An interesting cerambycid, which turned out to be Abryna regispetri Paiva, 1860 on the basis of available literature, was collected in Tripura in May 2011. Cambodia is the type locality (Paiva 1860), but it is so far known from Laos, Burma (now Myanmar) and Malaysia (Breuning 1962) and also from China, Borneo and Thailand (Roskov et al. 2014). Although many Burmese species are found in northeastern India, this one was not reported from any part of India until now. This becomes the first record of Abryna regispetri and hence an addition to the known fauna of Cerambycidae from India.

The genus Abryna was defined by Newman (1842) as a "doubtfully new genus" ("genus novum ?") while describing Abryna coenosa Newman, 1842. This fact was also pointed out by Westwood (1864) later. Breuning (1962) revised the Asiatic Pteropliini and gave keys for the species of this genus. He created the subgenus Faustabryna on the basis of the length of the third antennomere with respect to the fourth one (slightly longer in Abryna / distinctly longer in Faustabryna) and elytra narrowed in Abryna but longer and parallel sided in Faustabryna. Faustabryna Breuning, 1962, members of which often show metallic coloration of the elytra, is currently considered as a separate genus (Vives 2014).

Abryna regispetri was identified using the keys in Rondon \& Breuning (1970) and with a photograph of the species. Then, detailed characters of the genus were checked using generic (Newman 1842) and species original description (Paiva 1860), as well as that given by Breuning (1962). Since both these last descriptions are brief, not available in English and are without any illustrations, a detailed description of this species with illustrations is provided here. With this report, Tripura State in northeastern India is now known to have 26 species from 23 genera of longhorn beetles (Agarwala et al. 2014; Agarwala \& Bhattacharjee 2012, 2015).
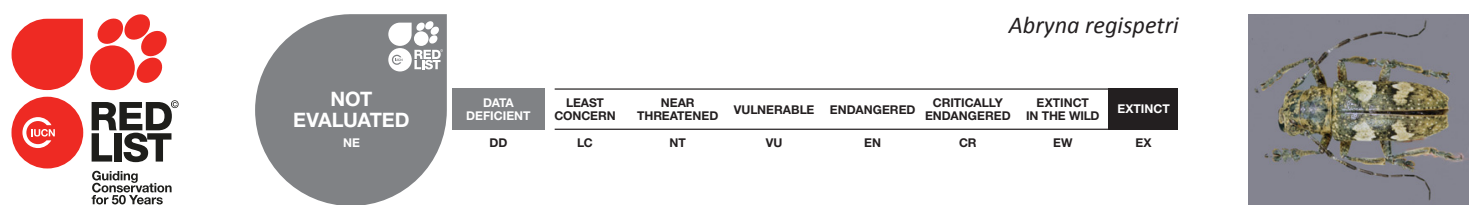

DOI: http://dx.doi.org/10.11609/jott.1839.7.14.8173-8176 | ZooBank: urn:Isid:zoobank.org:pub:43E9F5BB-3EB9-4CB8-9FD4-269CEAAACE79

Editor: Eduard Vives, Museu de Ciències Naturals de Barcelona, Terrassa, Spain.

Date of publication: 26 November 2015 (online \& print)

Manuscript details: Ms \# 04265 | Received 10 March 2015 | Final received 30 October 2015 | Finally accepted 07 November 2015

Citation: Ghate, H.V. \& B.K. Agarwala (2015). A first record of Abryna regispetri Paiva, 1860 (Cerambycidae: Lamiinae: Pteropliini) and its redescription from india. Journal of Threatened Taxa 7(14): 8173-8176; http://dx.doi.org/10.11609/jott.1839.7.14.8173-8176

Copyright: @ Ghate \& Agarwala 2015. Creative Commons Attribution 4.0 International License. JoTT allows unrestricted use of this article in any medium, reproduction and distribution by providing adequate credit to the authors and the source of publication.

Funding: This study was supported by Indian Council of Agricultural Research, New Delhi through a project grant no. F.No.16-16/2007-IA IV to the second author (B.K. Agarwala).

Conflict of Interest: The authors declare no competing interests.

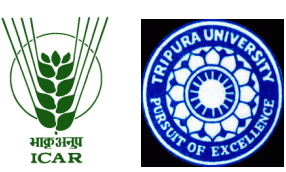

Acknowledgements: We are grateful to Indian Council of Agriculture Research, New Delhi for financial support through a research project on insect biosystematics, and to Francesco Vitali (Luxembourg) for providing much needed literature, for valuable comments and corrections in the first draft of this note. Thanks are due to the authorities of Modern College for facilities and encouragement. We also thank P. P. Bhattacharjee, R. Lodh and Dipankar Kishore Sinha for their collection efforts in field. 


\section{Abryna regispetri Paiva, 1860}

Specimen examined: Col/Cer/2939, 1, 12.v.2011, Trishna Wildlife Sanctuary, Tripura, collected in a light trap fitted with a 40W mercury lamp, Watkins \& Doncaster make, UK), sex not verified. Body length $25 \mathrm{~mm}$, breadth at humerus $8 \mathrm{~mm}$, elytra $15 \mathrm{~mm}$. Antennomeres: scape 5.3 , third $4 \mathrm{~mm}$ and fourth $3.5 \mathrm{~mm}$, deposited in the Department of Zoology, Modern College, Pune, India.

Redescription: Medium size beetle, form relatively stout, brown, elytra with pattern of spots and two transverse bands of a greyish white pubescence; sterna and abdomen largely covered with greyish-white pubescence and only few black spots of derma visible; legs stout, moderately long, compressed; posterior femora not exceeding elytral apex; antenna almost as long as body (Image 1).

Head with sloping forehead; mandibles long, dark brown, pointed at apex; maxillary and labial palps dark brown, shining, covered with sparse white setae; clypeus and forehead covered with greyish-white and brown pubescence, especially long at base of clypeus; forehead broad with fine median furrow running backwards onto vertex; antennal tubercles depressed, widely separated (Image 2); eyes large, coarsely faceted, divided into two lobes, upper lobe narrow and lower lobe almost twice as broad as wide; gena prominent, longer than lower eyelobe, widened near base of the mandibles so that this region projects outside in front of eyes (head is broadest at this level); gular region smooth and shining, with fine transverse lines; ventral region of head sparsely covered with pubescence (Image 3).

Antennae as long as body; antennomeres gradually becoming thinner distally; at least first four antennomeres show a few spots of grey or light brown pubescence; ventral side with short black and brown setae, which are sparsely distributed; scape distally swollen or globular; third antennomere longest; fourth slightly shorter than third; fifth onwards gradually decreasing in length (Image 1).

Pronotum wider than long, covered with a dark brown, light brown and greyish recumbent pubescence; sparsely and finely punctuate on disc; with hairless median dark line near anterior border and indistinct shallow median area in basal region that is again continued as median line anteriorly; a pair of lateral tubercles in anterior part, lower tubercle more prominent and close to anterior border, upper one smaller and slightly behind, both tubercles with a broad base and shining blunt tip; base with distinct transversal groove; apex with groove indistinct on disc but prominent laterally and ventrally.
Scutellum small, broader than long, half-moon shaped, concolourus with vertex and base of elytra (Image 5).

Elytra broader at base than prothorax; each elytron about four times as long as broad at humerus, more or less parallel sided, only gradually narrowing at posterior fourth and truncate apically with outer angle slightly produced, covered with dark brown, grey, whitish as well as brownish pubescence (Image 6); surface punctured uniformly throughout, punctures more clear in basal part and not in distinct rows (Image 7); elytra shining at spaces where pubescence is sparse; elsewhere dense pubescence of light colour forms a pattern of small greyish white spots and two broad transversal bands of irregular shape; first located before middle and second behind middle, both starting from elytral margins but not reaching suture (Images 6-7).

Prosternum distinctly raised above level of procoxae, anterior and posterior face strongly oblique. Mesosternum slightly raised above mesocoxae and directed anteriorly as blunt tubercle; metasternum much wider than long, deeply sinuate anteriorly behind mesocoxae and projecting in median region to meet mesosternum, densely covered with pubescence, posterior margin gently sinuate, with deep hairless furrow in median region, especially in posterior half (Image 4).

Abdomen with five visible segments, all equally long, their breadth decreasing distally; first abdominal segment with small angular process that projects forward between the posterior coxae and meets metasternum; procoxal cavity angularly extended outward, mesocoxal cavity open to mesepimeron; metepisternum very narrow; all sternites covered with pale cream pubescence denser and longer in apical half of each segment, dark brown derma visible at places (Image 8).

Legs of moderate length, covered with pubescence forming a pattern of spots like that on antenna and elytra; femora only slightly broader in median region; tarsal segments prominent and broad; first and second tarsal segment without distinct median suture, third distinctly bilobed (Image 8).

An estimated 33,140 species of Cerambycidae are known from the world (Tavakilian \& Chevillotte 2014). Tropical parts on both sides of the equator are most rich in biodiversity (Myers et al. 2000) and hold much of the animal diversity which is unknown or poorly known (Mittermeier et al. 2005). Northeastern India, being part of the Indo-Myanmar mega hot spot of biodiversity, is home to 168 currently known species of longicorn beetles (Gahan1894; Dillon \& Dillon 1950; Sengupta \& 

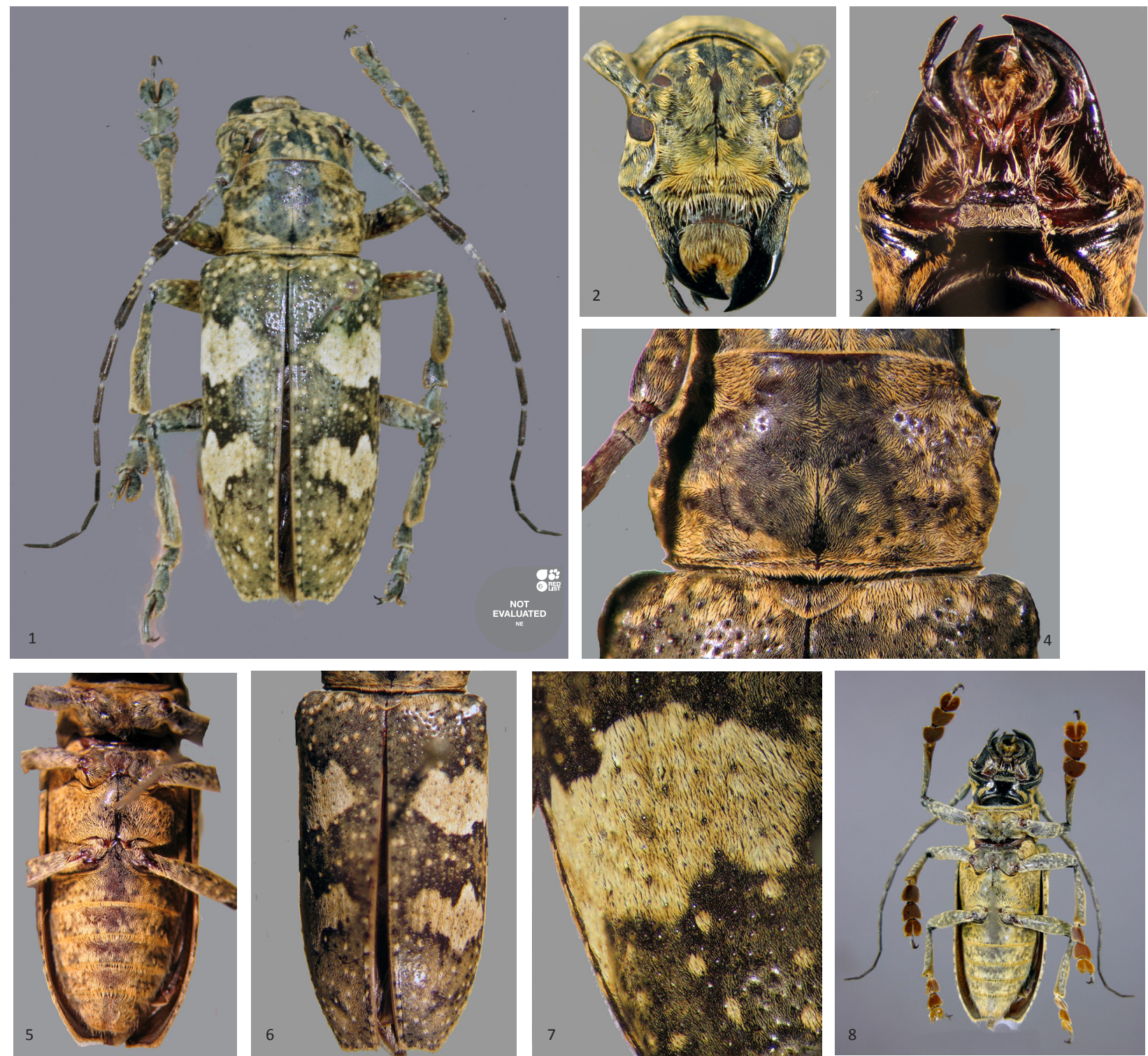

Images 1-8. Various views of Abryna regispetri.

1 - Full Dorsal view showing bands and other patterns of pubescence; 2 - Frontal view of head showing pubescence, coarsely facetted eyes and shape of front; 3 - Ventral view of head showing glossy gular area, dark mandibles and palps; 4 - Dorsal view of pronotum showing sparse puncturation and lateral tubercles; 5 - Ventral view of thorax and abdomen showing sterna and abdominal segments and pattern of pubescence; 6 - Dorsal view of elytra showing the coloration and sparse punctures; 7 - Magnified view of elytral band showing different coloration of pubescence; 8 - Full ventral view. (C) Hemant V. Ghate

Sengupta 1981; Mukhopadhyay \& Biswas 2000, 2002; Mukhopadhyay \& Halder 2004; Agarwala \& Bhattacharjee 2012; Agarwala et al. 2014; Mitra \& Majumder 2014; Agarwala \& Bhattacharjee 2015). Many of these species were described before 1950 and are data deficient. More recently, Mitra \& Majumder (2014) reported 12 species of the family as new records from Arunachal Pradesh, and Vives \& Ghate (2015) reported and redescribed two species of longhorn beetles, Anoeme andrewesi Gahan, 1906 (Prioninae, Meroscelisini) and Zoodes maculatus (White, 1855), (Cerambycinae, Hesperophanini), the latter as new additions from India. With this background, the redescription of $A$. regispetri of Southeast Asia origin with current distribution extending to India is an advancement of the taxonomic study of these insects.

\section{Refrences}

Agarwala, B.K. \& P.P. Bhattacharjee (2012). Long-horned beetles (Coleoptera: Cerambycidae) and Tortoise beetles (Chrysomelidae: Cassidinae) of Tripura, northeastern India with some new additions. Journal of Threatened Taxa 4(13): 3223-3227; http://dx.doi. org/10.11609/JoTT.02951.3223.7 
Agarwala, B.K., H.V. Ghate \& P.P. Bhattcharajee (2014). Redescriptions of Imantocera penicillata Hope and Eutaenia corbetti Gahan (Coleoptera: Cerambycidae), with records of host plants from India. The Coleopterists Bulletin 68(4): 719-726; http://dx.doi.org/10.1649/0010-065x-68.4.719

Agarwala, B.K. \& P.P. Bhattacharjee (2015). Redescription of Aristobia reticulator (F., 1781) (Coleoptera: Cerambycidae: Lamiinae), with a taxonomic note and record of a new food plant of adults in northeastern India. The Coleopterists Bulletin 69(2): 205-212; http://dx.doi. org/10.1649/0010-065x-69.2.205

Dillon, L.S. \& E.S. Dillon (1950). The Lamiine tribe Gnomini (Coleoptera, Cerambycidae). The Philippine Journal of Science 79: 11-57.

Gahan, C.J. (1894). A list of the longicorn Coleoptera collected by Signor Fea in Burma and the adjoining regions, with description of new genera and species. Annali del Museo Civico di Storia Naturale de Genova 34: 5-104.

Mitra, B. \& A. Majumder (2014). New records of longicorn beetles from Arunachal Pradesh (Coleoptera: Cerambycidae) Bionotes 16(1): 25-26.

Mittermeier, R.A., P.R. Gill, M. Hoffman, J. Pilgrim, T. Brooks, C.G. Mittermeier, J. Lamoreux \& G.A.B. da Fonseca (2005). Hotspots Revisited: Earth's Biologically Richest and most Endangered Terrestrial Ecoregions. CEMEX, Mexico, 392pp. http://www.press.uchicago.edu/ ucp/books/book/distributed/H/bo3707156.html

Mukhopadhyay, P. \& S. Biswas (2000). Coleoptera: Cerambycidae, pp. 41-67. In: Director (ed.). State Fauna Series 4, Fauna of Meghalaya: Part 5, Zoological Survey of India Publications, Kolkata, India.

Mukhopadhyay, P. \& S. Biswas (2002). Coleoptera: Cerambycidae, pp. 139-142. In: Director (ed.). State Fauna Series 7, Fauna of Tripura: Part 3, Zoological Survey of India Publications, Kolkata, India.

Mukhopadhyay, P. \& S. K. Halder (2004). Insecta: Coleoptera: Cerambycidae, pp. 421-431. In: Director (ed.) State Fauna Series 10 Fauna of Manipur: Part 2, Zoological Survey of India Publications, Kolkata, India.

Myers, N., C.G. Mittermeyer, G.A.B. Fonseca \& J. Kent (2000). Biodiversity hotspots for conservation priorities. Nature 403: 853-858; http:// dx.doi.org/10.1038/35002501

Newman, E. (1842). Cerambycitum Insularum Manillarum Dom. Cuming captorum enumeratio digesta. The Entomologist 15: 288-293.

Paiva, de B.D.C. (1860). Descriptions of two Coleopterous insects from Cambogia. The Annals and Magazine of Natural History Series 3(6): 360-362.

Rondon, J.A. \& S. von Breuning (1970). Lamiines du Laos, pp. 315-571. In: Gressitt, J.L., J.A. Rondon \& S. Breuning, von (eds.). Cerambycid-beetles of Laos (Longicornes du Laos). Pacific Insects' Monograph 24, Bernice P. Bishop Museum, Honolulu, 651pp.

Roskov, Y., T. Kunze T. Orrell, L. Abucay, L. Paglinawan, A. Culham, N. Bailly, P. Kirk, T. Bourgoin, G. Baillargeon, W. Decock, A. de Wever \& V. Didžiulis (eds.) (2014). Species 2000 \& ITIS Catalogue of Life, 2014 Annual Checklist. www.catalogueoflife.org/annual-checklist/2014. Species 2000: Naturalis, Leiden, the Netherlands, accessed on 20 February 2015.

Sengupta, C.K. \& T. Sengupta (1981). Cerambycidae (Coleoptera) of Arunachal Pradesh. Records of the Zoological Survey of India 78: 133154.

Tavakilian G. \& H. Chevillotte (2014). TITAN: Cerambycidae database (version 12 October 2011). In: Roskov, Y., T. Kunze T. Orrell, L. Abucay, L. Paglinawan, A. Culham, N. Bailly, P. Kirk, T. Bourgoin, G. Baillargeon, W. Decock, A. de Wever \& V. Didžiulis ( eds). Species 2000 \& ITIS Catalogue of Life, 2014 Annual Checklist. Digital resource at www.catalogueoflife. org/annual-checklist/2014, Species 2000: Naturalis, Leiden, the Netherlands, accessed on 20 February 2015

Vives, E. (2014). New or interesting Cerambycidae from Philippines (VIII): the genus Faustabryna Breuning, 1961 (Coleoptera, Cerambycidae, Lamiinae). Les Cahiers Magellanes (NS) 15: 6-13;

Vives, E. \& H.V. Ghate (2015). On two rare cerambycid beetles (Coleoptera) from India. Taprobanica 7(1): 40-42.

von Breuning, S. (1962). Bestimmungstabelle der Lamiiden - Triben nebst Revison der Pteropliini der Asiatschen Region. Teil. 1. Entomologische Arbeiten aus dem Museum G. Frey Tutzing, 13: 371-493; http://www. cerambycoidea.com/titles/breuning1962c.pdf

Westwood, J.O. (1864). Descriptions of some new species of exotic longicorn beetles. Transactions of the Entomological Society of London 1 (3rd series): $625-636$. 